\title{
CONSUMPTIVE USE PROGRAM (CUP) MODEL
}

\author{
Morteza N. Orang ${ }^{1}$ \\ Richard L. Snyder ${ }^{2}$ \\ J. Scott Matyac ${ }^{3}$
}

\begin{abstract}
For many years, published crop efficient $\left(K_{\mathrm{c}}\right)$ values have been used to estimate crop evapotranspiration $\left(\mathrm{ET}_{\mathrm{c}}\right)$ from reference evapotranspiration $\left(\mathrm{ET}_{0}\right)$. The Consumptive Use Program (CUP) was developed to improve estimates of $K_{\mathrm{c}}$ and $\mathrm{ET}_{\mathrm{c}}$ values to aid in California water planning. CUP computes $\mathrm{ET}_{0}$ from mean monthly values for solar radiation, maximum, minimum, and dew point temperature, and wind speed. From this, the program uses a curve-fitting technique to produce daily $\mathrm{ET}_{0}$ and rainfall data for a year. Bare soil evaporation is used to estimate $K_{\mathrm{c}}$ values for the off-season and as a baseline for early season $K_{\mathrm{c}}$ calculations. One improvement is to account for the influence of rainfall and/or irrigation frequency on $K_{\mathrm{c}}$ and $\mathrm{ET}_{\mathrm{c}}$ during initial growth. For tree crops, it is important to account for cover crops, which has not been done in the past. Another improvement is to compute and apply all $\mathrm{ET}_{\mathrm{o}}$ and $K_{\mathrm{c}}$ values on a daily basis to determine crop water requirements. Using new information on midseason $K_{\mathrm{c}}$ values and bare soil evaporation, a user-friendly Excel program, CUP, was developed to improve long-term estimates that account for rainfall, cover crop, and immaturity effects. This paper presents the advantages of CUP.
\end{abstract}

\section{INTRODUCTION}

A user-friendly Microsoft Excel computer program, CUP was developed to help growers and water agencies determine crop coefficient $\left(K_{\mathrm{c}}\right)$ values and crop evapotranspiration $\left(E T_{c}\right)$. California needs long-term estimates of $E T_{c}$ for water planning. CUP, written by M. N. Orang with assistance from R. L. Snyder and J. $S$. Matyac, was designed to account for factors affecting $K_{\mathrm{c}}$ that are generally ignored in other water requirement programs. For example, the program provides estimates of nearly bare soil evaporation during initial growth of crops based on $E T_{0}$ rates and irrigation or rainfall frequency. Because California growers do not

\footnotetext{
${ }^{1}$ Associate land and water use analyst, California Department of Water Resources - Division of Planning and Local Assistance, PO Box 942836, Sacramento, CA 94236-0001

${ }^{2}$ Biometeorologist, University of California, Atmospheric Science, Davis, CA 95616

${ }^{3}$ Senior land and water use analyst, California Department of Water Resources Division of Planning and Local Assistance, PO Box 942836, Sacramento, CA 94236-0001
} 
use metric units, CUP's input and output data are in English units. However, in the near future, the program will be converted to metric and translated into Spanish.

\section{WORKSHEETS}

CUP has 14 Excel worksheets. The first six worksheets are "Disclaimer," "HelpAbout," "HELP," "ET, Zones Map," "ET, Zones," and "Weather Input." "HelpAbout" provides information about the program. "HELP" explains the components of the program and provides step-by-step instructions for inputting data into the program. "ET, Zones" contains a map showing 18 zones of similar $\mathrm{ET}_{0}$ rates for California. The map was developed by D. Jones, R.L. Snyder, S. Eching, and H. Gomez-MacPherson. The "Weather Input" worksheet is used to input monthly mean weather data for calculating $\mathrm{ET}_{0}$.

$\mathrm{ET}_{0}$ and crop data are entered into the "Input_Output" worksheet, which then displays the summary of inputs and monthly and seasonal outputs. The "Calculations" worksheet shows all of the growth dates and $K_{\mathrm{c}}$ values as well as the daily calculations of $\mathrm{ET}_{0}, K_{\mathrm{c}}$, and $\mathrm{ET}_{\mathrm{c}}$ for each of the growth periods. The " $K_{\mathrm{c}}$ Chart" shows a plot of the calculated seasonal crop coefficients with colored lines representing each growth period. Charts "RainInitGrow" and "IrrigInitGrow" show plots of $K_{\mathrm{c}}$ versus mean $\mathrm{ET}$ 。 rates. The chart "RainInitGrow" shows the nearly bare soil $K_{\mathrm{c}}$ corresponding to the mean initial growth period $\mathrm{ET}_{\mathrm{o}}$ rate and soil wetting frequency by rainfall. The chart "IrrigInitGrow" shows the nearly bare soil $K_{\mathrm{c}}$ corresponding to mean $\mathrm{ET}_{\mathrm{o}}$ rate and soil wetting frequency by irrigation.

Rainfall or irrigation wetting frequencies are entered into the "Input_Output" worksheet, and the charts are automatically displayed. If the $K_{\mathrm{c}}$ resulting from surface wetting is bigger than the table value during early crop growth, the larger $K_{\mathrm{c}}$ value is used. There are also summary worksheets for $K_{\mathrm{c}}$ values, $\mathrm{ET}_{\mathrm{o}}$, and $\mathrm{ET}_{\mathrm{c}}$. After data entry, the current crop information and calculated $K_{\mathrm{c}}$ data in the "Input_Output" worksheet can be printed to one row in the "Summary of $K_{\mathrm{c}}$ " worksheet. $\mathrm{ET}_{\mathrm{o}}$ data are printed to "Summary of $\mathrm{ET}_{\mathrm{o}}$," and $\mathrm{ET}_{\mathrm{c}}$ data are printed

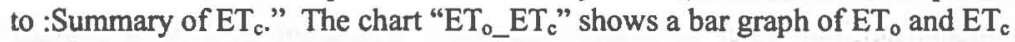
totals by month for the current crop information. The "Crop References" worksheet contains estimated growth date and $K_{\mathrm{c}}$ information, which are used as default values in the program.

\section{INPUT_OUTPUT WORKSHEET}

Crop information is entered into cells on the left-hand side of the 'Input_Output' worksheet. To enter pan data, 77 is input into the $\mathrm{ET}_{0}$ Zone number cell; to use monthly weather data, 88 is entered into the cell; and to enter raw ET $\mathrm{ET}_{0}$ data, 99 is input. Next a crop number is entered into the Crop Number cell. CUP provides a 
list of crops and crop numbers in the 'Crop References' worksheet. That worksheet also contains the percentage of the season to various growth dates (explained later), $K_{\mathrm{c}}$ values at critical growth points, and sample start and end dates for the season.

Note that the crop numbers have one digit to the left and two digits to the right of a decimal point. The single digit identifies the crop type, and the double digit identifies the crop. When a crop is selected, the growth, $K_{\mathrm{c}}$ value, and default start-end information is automatically used for the calculations. The start date corresponds to planting for field and row crops and to leaf-out date for tree and vine crops. Nondeciduous trees, turfgrass, and pasture crops start on January 1 and end on December 31. If different from the default values, the start and end dates can be changed in the "Input_Output" worksheet.

Initial $K_{\mathrm{c}}$ value for most crops is affected by and, thus, depends on wetting frequency from rainfall and/or irrigation. As canopy shading increases, the contribution of soil evaporation to $\mathrm{ET}_{\mathrm{c}}$ decreases while the contribution of transpiration increases. In the "Input_Output" worksheet, the rainfall frequency during early growth is entered to determine a $K_{\mathrm{c}}$ value for nearly bare soil evaporation. Similarly, irrigation frequency is entered and a $K_{\mathrm{c}}$ value determined for nearly bare soil evaporation during initial growth of field and row crops. CUP compares $K_{\mathrm{c}}$ values from the "Crop References" worksheet with those based on rainfall and irrigation frequency and selects the largest of the three for use in calculating $\mathrm{ET}_{\mathrm{c}}$. If no rainfall or irrigation frequency is entered, the $K_{\mathrm{c}}$ value from the A-B column in the "Crop References" worksheet is used as the initial growth $K_{\mathrm{c}}$ value. The starting $K_{\mathrm{c}}$ value for type-2 crops (for example, turfgrass and pasture) and for type -4 crops (for example, subtropical orchards) is not affected by irrigation or rainfall frequency entries.

Cover crops affect $\mathrm{ET}_{\mathrm{c}}$ rates, and CUP accounts for the effects. Cover crop start and end dates are entered into cells under "Enter $1^{\text {st }}$ Cover Crop (day/mon)." Because some crops have cover crops in spring and fall but not in the summer, a second set of cover crop dates can be input under "Enter $2^{\text {nd }}$ Cover Crop (day/mon)." During a period with a cover crop, the value 0.35 is added to the "clean cultivated" $K_{\mathrm{c}}$ value. However, the $K_{\mathrm{c}}$ value is not allowed to exceed 1.15 or to fall below 0.90 .

The right-hand side of the "Input_Output" worksheet shows the weighted mean $K_{\mathrm{c}}, \mathrm{ET}_{\mathrm{o}}, \mathrm{ET}_{\mathrm{c}}$, and seasonal $\mathrm{ET}_{\mathrm{c}}$ values by month for the selected crop and input information. The daily mean $\mathrm{ET}_{\mathrm{o}}$ rates by month are also shown below the other data. Below that set of cells, there are "Copy/Paste" and "Delete" buttons. When the "Copy/Paste" button is pressed, results of the calculations are sent to "Summary ET," "Summary $K_{\mathrm{c}}$," and "Summary ET " worksheets. The "Delete" button clears all entries from the summary worksheets. To retain all of the data entries, save the CUP file as an Excel workbook with a different name. To save 
only the summary sheets, display the summary sheet and save as a tab or comma delimited file. After saving the desired output data, click the "Delete" button to erase data from the summary worksheets.

\section{CAlCulation}

The "Calculation" worksheet shows the selected and input data as well as critical dates for growth and cover crops and the daily calculations of $\mathrm{ET}_{0}, K_{\mathrm{c}}$, and $\mathrm{ET}_{\mathrm{c}}$ values by the growth stages. The main factors affecting the difference between $\mathrm{ET}_{\mathrm{c}}$ and $\mathrm{ET}_{\mathrm{o}}$ are (1) light absorption by the canopy, (2) canopy roughness, which affects turbulence, (3) crop physiology, (4) leaf age, and (5) surface wetness. When not limited by water availability, both transpiration and evaporation are limited by the availability of energy to vaporize water. Therefore, for unstressed crops, solar radiation (or light) interception by the foliage and soil mainly affect the $\mathrm{ET}_{\mathrm{c}}$ rate.

As field and row crops grow, the canopy cover, light interception, and the ratio of transpiration (T) to ET increases until most of the ET comes from $\mathrm{T}$ and evaporation (E) is a minor component. The $K_{\mathrm{c}}$ value increases with canopy cover until reaching about $75 \%$ cover. For tree and vine crops the peak $K_{\mathrm{c}}$ value is reached when the canopy has reached about $70 \%$ ground cover. The difference between the crop types is because light interception is higher for the taller crops.

\section{FIELD AND ROW CROP $K_{C}$ VALUES}

Field and row crop $K_{\mathrm{c}}$ values are calculated using a method similar to that described by Doorenbos and Pruitt (1977). A generalized curve is shown in Figure 1. In their method, the season is separated into initial (date A-B), rapid (date B-C), midseason (date C-D), and late season (date D-E) growth periods. $K_{\mathrm{c}}$ values are denoted $K_{\mathrm{c}} \mathrm{A}, K_{\mathrm{c}} \mathrm{B}, K_{\mathrm{c}} \mathrm{C}, K_{\mathrm{c}} \mathrm{D}$, and $K_{\mathrm{c}} \mathrm{E}$ at the ends of the A, B, C, D, and $\mathrm{E}$ growth dates, respectively. During initial growth, the $K_{\mathrm{c}}$ values are a constant value, so $K_{\mathrm{c}} \mathrm{A}=K_{\mathrm{c}} \mathrm{B}$. During the rapid growth period, when the canopy increases from about $10 \%$ to $75 \%$ ground cover, the $K_{\mathrm{c}}$ value increases linearly from $K_{\mathrm{c}} \mathrm{B}$ to $K_{\mathrm{c}} \mathrm{C}$. The $K_{\mathrm{c}}$ values are also at a constant value during midseason, so $K_{\mathrm{c}} \mathrm{C}=K_{\mathrm{c}} \mathrm{D}$. During late-season, the $K_{\mathrm{c}}$ values decrease linearly from $K_{\mathrm{c}} \mathrm{D}$ to $K_{\mathrm{c}} \mathrm{E}$ at the end of the season. 


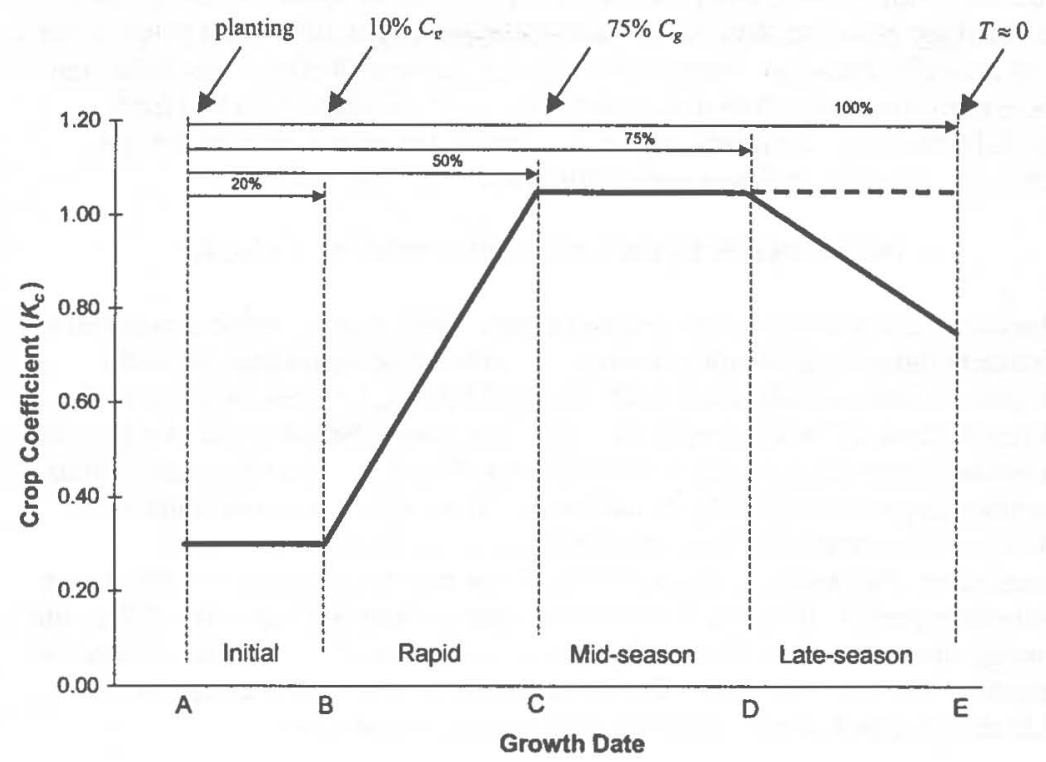

Figure 1. Hypothetical crop coefficient curve for field and row crops using percentage of the season to delineate growth dates. The dashed line is for fresh market crops with no late-season $K_{\mathrm{c}}$ value drop (that is, there is no date D).

Doorenbos and Pruitt (1977) provide estimated number of days for each of the four growth periods to help identify the end dates of growth periods. However, because there are climate and varietal differences and because it is difficult for growers to know when the inflection points occur, irrigators often find this confusing. To simplify this problem, CUP uses percentages of the season from planting to each inflection point rather than days in growth periods (see Figure 1). Irrigation planners need only enter the planting and end dates. The intermediate dates are determined from the percentages, which are easily stored in a computer program.

During initial growth of field and row crops, the default $K_{\mathrm{c}}$ value $\left(K_{\mathrm{c}} 1\right)$ is used for $K_{\mathrm{c}} \mathrm{A}$ and $K_{\mathrm{c}} \mathrm{B}$ unless it is overridden by a $K_{\mathrm{c}}$ value based on rainfall or irrigation frequency. If a soil wetting-based $K_{\mathrm{c}} 1$ is desired, the irrigation or rainfall frequency is entered in the "Input_Output" worksheet. Then, a graph showing the $K_{\mathrm{c}}$ values curve corresponding to input wetting frequency versus mean $\mathrm{ET}_{0}$ rate is shown in the chart "IrrigInitGrow" or "RainInitGrow," respectively, for irrigation or rainfall entries. 
The values for $K_{\mathrm{c}} \mathrm{C}=K_{\mathrm{c}} \mathrm{D}$ depend on (1) light interception differences, (2) crop morphology effects on turbulence, and (3) physiological differences between the crop and reference crop. Some field crops are harvested before senescence, and there is no late season drop in $K_{\mathrm{c}}$ values (for example, silage corn and fresh market tomatoes). Relatively constant annual $K_{\mathrm{c}}$ values are possible for some crops (for example, turfgrass and pasture) with little loss in accuracy.

\section{DECIDUOUS TREE AND VINE CROP $K_{C}$ VALUES}

Deciduous tree and vine crops, without a cover crop, have $K_{\mathrm{c}}$ value curves that are similar to those for field and row crops but without the initial growth period (Figure 2). Default $K_{\mathrm{c}} \mathrm{B}, K_{\mathrm{c}} \mathrm{C}=K_{\mathrm{c}} \mathrm{D}=K_{\mathrm{c}} 2$ and $K_{\mathrm{c}} \mathrm{E}=K_{\mathrm{c}} 3$ values are given in the "Crop References" worksheet of the CUP. The season begins with rapid growth at leaf out when the $K_{\mathrm{c}}$ value increases from $K_{\mathrm{c}} \mathrm{B}$ to $K_{\mathrm{c}} \mathrm{C}$. The midseason period begins at approximately $70 \%$ ground cover. Then, unless the crop is immature, the $K_{\mathrm{c}}$ value is relatively fixed between dates $\mathrm{C}$ and $\mathrm{D}$ until the onset of senescence. For immature crops, canopy cover may be less than $70 \%$ during the midseason period. If so, the $K_{\mathrm{c}}$ value will increase from $K_{\mathrm{c}} \mathrm{C}$ up to the $K_{\mathrm{c}} \mathrm{D}$ as the canopy cover increases. The CUP program does account for $K_{\mathrm{c}}$ value changes of immature tree and vine crops. During late season, the $K_{\mathrm{c}}$ value decreases from $K_{\mathrm{c}} \mathrm{D}$ to $K_{\mathrm{c}} \mathrm{E}$, which occurs when the transpiration is near zero.

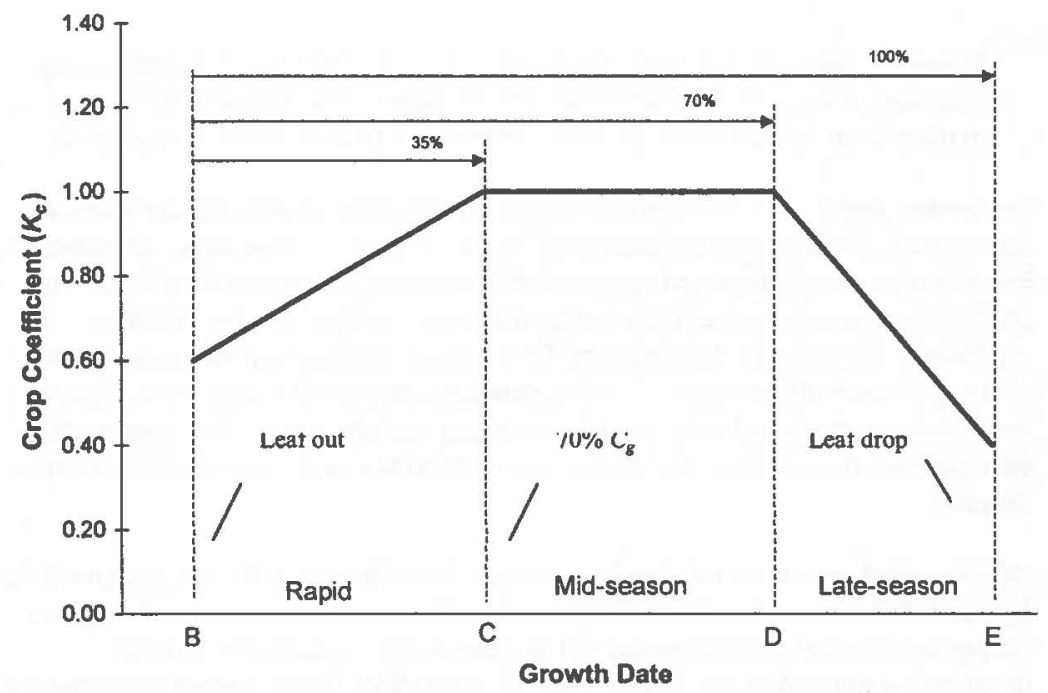

Figure 2. Hypothetical crop coefficient curve for deciduous tree and vine crops using percentage of the season to delineate growth dates. There is no initial growth period, so the season starts at leaf out on date B. 


\section{Correcting $\mathbf{K}_{\mathrm{S}} \mathbf{B}$ for soil evaporation}

Initially, the $K_{\mathrm{c}}$ value for deciduous trees and vines $\left(K_{\mathrm{c}} \mathrm{B}\right)$ is selected from a table of default values. However, ET is mainly soil evaporation at leaf out, so CUP contains the methodology to determine a corrected $K_{\mathrm{c}} \mathrm{B}$, based on the bare soil evaporation.

\section{Correcting for cover crops}

With a cover crop, the $K_{\mathrm{c}}$ values for deciduous trees and vines are higher. When a cover crop is present, 0.35 is added to the clean-cultivated $K_{\mathrm{c}}$. However, the $K_{\mathrm{c}}$ value is not allowed to exceed 1.15 or to fall below 0.90 . CUP allows beginning and end dates to be entered for two periods when a cover crop is present in an orchard or vineyard.

\section{Immature trees and vines}

Immature deciduous tree and vine crops use less water than mature crops. The following equation is used to adjust the mature $K_{\mathrm{c}}$ values $\left(K_{\mathrm{cm}}\right)$ as a function of percentage of ground cover $\left(\mathrm{C}_{\mathrm{g}}\right)$.

$$
\text { If } \sin \left(\frac{C_{g}}{70} \frac{\pi}{2}\right) \geq 1.0 \text { then } K_{c}=K_{c m} \text { else } K_{c}=K_{c m}\left[\sin \left(\frac{C_{g}}{70} \frac{\pi}{2}\right)\right]
$$

\section{Subtropical orchards}

For mature subtropical orchards (for example, citrus), using a fixed $K_{\mathrm{c}}$ value during the season provides acceptable $\mathrm{ET}_{\mathrm{c}}$ estimates. However, if higher, the bare soil $K_{\mathrm{c}}$ value is used for the orchard $K_{\mathrm{c}}$ value. For an immature orchard, the mature $K_{\mathrm{c}}$ values $\left(K_{\mathrm{cm}}\right)$ are adjusted for percentage of ground cover $\left(\mathrm{C}_{\mathrm{g}}\right)$ using the following criteria.

$$
\text { If } \sqrt{\sin \left(\frac{C_{g}}{70} \frac{\pi}{2}\right)} \geq 1.0 \text { then } K_{\mathrm{c}}=K_{c m} \text { or else } K_{c}=K_{c m} \sqrt{\sin \left(\frac{C_{g}}{70} \frac{\pi}{2}\right)}
$$

\section{Field crops and landscape covers with fixed $K_{c}$ values}

Some field crops and landscape plants (type-2 crops) have a fixed $K_{\mathrm{c}}$ value all year. However, if the significant rainfall frequency is sufficient to have a higher $K_{\mathrm{c}}$ value for bare soil than for the selected crop, then the higher bare soil $K_{\mathrm{c}}$ should be used. CUP permits entry of monthly mean rainfall frequency data. If entered, daily $K_{\mathrm{c}}$ values for bare soil evaporation are computed for the entire year. The higher of the fixed crop $K_{\mathrm{c}}$ value or the bare soil $K_{\mathrm{c}}$ value is used to estimate 
$\mathrm{ET}_{\mathrm{c}}$ for the crop. If no rainfall frequency data are entered, then the fixed crop $K_{\mathrm{c}}$ value is used.

\section{ESTIMATING BARE SOIL $K_{C}$ VALUES}

A soil evaporation $K_{\mathrm{c}}$ value, based on $\mathrm{ET}_{0}$ and rainfall frequency is needed as a minimum (baseline) for estimating $\mathrm{ET}_{\mathrm{c}}$. It is also useful to determine the $K_{\mathrm{c}}$ value during initial growth for field and row crops $\left(K_{\mathrm{c}} 1=K_{\mathrm{c}} \mathrm{A}=K_{\mathrm{c}} \mathrm{B}\right)$ and the starting $K_{\mathrm{c}}$ for deciduous tree and vine crops $\left(K_{\mathrm{c}} \mathrm{l}=K_{\mathrm{c}} \mathrm{B}\right)$ based on irrigation frequency. The $K_{\mathrm{c}}$ values used to estimate bare soil evaporation are based on a two-stage soil evaporation method reported by Stroonsnjider (1987) and refined by Snyder et al. (2000). The method provides a $K_{c}$ values as a function of $\mathrm{ET}_{0}$ rate and wetting frequency that are similar to those published in Doorenbos and Pruitt (1977).

When mean monthly weather and ET, data are entered into the "Weather Input" worksheet, including the number of significant rainy days per month, CUP calculates a baseline soil evaporation curve. Daily precipitation is considered significant when $P_{s}>2 \times \mathrm{ET}_{0}$. Whenever, the $K_{\mathrm{c}}$ value for bare soil evaporation is higher than the $K_{\mathrm{c}}$ value based on table or calculated $K_{\mathrm{c}}$ values, the higher $K_{\mathrm{c}}$ value is used.

\section{REFERENCES}

Doorenbos, J. and Pruitt, W.O. 1977. Crop water requirements. Rev. 1977. FAO Irrig. and Drain. Paper 24, FAO of the United Nations, Rome. pp. 144.

Snyder, R.L., Bali, K., Ventura, F, and Gomez-MacPherson, H. 2000. Estimating evaporation from bare or nearly bare soil, J. Irrig. Drain. Div. Am. Soc. Civ. Eng. 126(6): 399-403.

Stroosnijder, L. 1987. Soil evaporation: test of a practical approach under semiarid conditions. Neth. J. of Agric. Sci., 35: 417-426. 